Microinjection 


\section{ME THODS I N M OLE C ULA R B I O L O G Y TM}

\section{John M. Walker, SERIES EDITOR}

518. Microinjection: Methods and Applications, edited by David J. Carroll, 2009

502. Bacteriophages: Methods and Protocols, Volume 2: Molecular and Applied Aspects, edited by Martha R. J. Clokie and Andrew M. Kropinski, 2009

501. Bacteriophages: Methods and Protocols, Volume 1: Isolation, Characterization, and Interactions, edited by Martha R. J. Clokie and Andrew M. Kropinski, 2009

496. DNA and RNA Profiling in Human Blood: Methods and Protocols, edited by Peter Bugert, 2009

493. Auditory and Vestibular Research: Methods and Protocols, edited by Bernd Sokolowski, 2009

490. Protein Structure, Stability, and Interactions, edited by John W. Shriver, 2009

489. Dynamic Brain Imaging: Methods and Protocols, edited by Fahmeed Hyder, 2009

485. HIV Protocols: Methods and Protocols, edited by Vinayaka R. Prasad and Ganjam V. Kalpana, 2009

484. Functional Proteomics: Methods and Protocols, edited by Julie D. Thompson, Christine Schaeffer-Reiss, and Marius Ueffing, 2008

483. Recombinant Proteins From Plants: Methods and Protocols, edited by Lóic Faye and Veronique Gomord, 2008

482. Stem Cells in Regenerative Medicine: Methods and Protocols, edited by Julie Audet and William L. Stanford, 2008

481. Hepatocyte Transplantation: Methods and Protocols, edited by Anil Dhawan and Robin D. Hughes, 2008

480. Macromolecular Drug Delivery: Methods and Protocols, edited by Mattias Belting, 2008

479. Plant Signal Transduction: Methods and Protocols, edited by Thomas Pfannschmidt, 2008

478. Transgenic Wheat, Barley and Oats: Production and Characterization Protocols, edited by Huw D. Jones and Peter R. Shewry, 2008

477. Advanced Protocols in Oxidative Stress I, edited by Donald Armstrong, 2008

476. Redox-Mediated Signal Transduction: Methods and Protocols, edited by John T. Hancock, 2008

475. Cell Fusion: Overviews and Methods, edited by Elizabeth H. Chen, 2008

474. Nanostructure Design: Methods and Protocols, edited by Ehud Gazit and Ruth Nussinov, 2008

473. Clinical Epidemiology: Practice and Methods, edited by Patrick Parfrey and Brendon Barrett, 2008

472. Cancer Epidemiology, Volume 2: Modifiable Factors, edited by Mukesh Verma, 2008

471. Cancer Epidemiology, Volume 1: Host Susceptibility Factors, edited by Mukesh Verma, 2008

470. Host-Pathogen Interactions: Methods and Protocols, edited by Steffen Rupp and Kai Sobn, 2008

469. Wnt Signaling, Volume 2: Pathway Models, edited by Elizabeth Vincan, 2008
468. Wnt Signaling, Volume 1: Pathway Methods and Mammalian Models, edited by Elizabeth Vincan, 2008

467. Angiogenesis Protocols: Second Edition, edited by Stewart Martin and Cliff Murray, 2008

466. Kidney Research: Experimental Protocols, edited by Tim D. Hewitson and Gavin J. Becker, 2008

465. Mycobacteria, Second Edition, edited by Tanya Parish and Amanda Claire Brown, 2008

464. The Nucleus, Volume 2: Physical Properties and Imaging Methods, edited by Ronald Hancock, 2008

463. The Nucleus, Volume 1: Nuclei and Subnuclear Components, edited by Ronald Hancock, 2008

462. Lipid Signaling Protocols, edited by Banafshe Larijani, Rudiger Woscholski, and Colin A. Rosser, 2008

461. Molecular Embryology: Methods and Protocols, Second Edition, edited by Paul Sharpe and Ivor Mason, 2008

460. Essential Concepts in Toxicogenomics, edited by Donna L. Mendrick and William B. Mattes, 2008

459. Prion Protein Protocols, edited by Andrew F. Hill, 2008

458. Artificial Neural Networks: Methods and Applications, edited by David S. Livingstone, 2008

457. Membrane Trafficking, edited by Ales Vancura, 2008

456. Adipose Tissue Protocols, Second Edition, edited by Kaiping Yang, 2008

455. Osteoporosis, edited by Jennifer J.Westendorf, 2008

454. SARS- and Other Coronaviruses: Laboratory Protocols, edited by Dave Cavanagh, 2008

453. Bioinformatics, Volume 2: Structure, Function, and Applications, edited by Jonathan M. Keith, 2008

452. Bioinformatics, Volume 1: Data, Sequence Analysis, and Evolution, edited by Jonathan M. Keith, 2008

451. Plant Virology Protocols: From Viral Sequence to Protein Function, edited by Gary Foster, Elisabeth Johansen, Yiguo Hong, and Peter Nagy, 2008

450. Germline Stem Cells, edited by Steven X. Hou and Shree Ram Singh, 2008

449. Mesenchymal Stem Cells: Methods and Protocols, edited by Darwin J. Prockop, Douglas G. Phinney, and Bruce A. Brunnell, 2008

448. Pharmacogenomics in Drug Discovery and Development, edited by Qing Yan, 2008

447. Alcohol: Methods and Protocols, edited by Laura E. Nagy, 2008

446. Post-translational Modifications of Proteins: Tools for Functional Proteomics, Second Edition, edited by Christoph Kannicht, 2008

445. Autophagosome and Phagosome, edited by Vojo Deretic, 2008

444. Prenatal Diagnosis, edited by Sinhue Habn and Laird G. Jackson, 2008

443. Molecular Modeling of Proteins, edited by Andreas Kukol, 2008 


\title{
Methods in Molecular Biology
}

\section{Microinjection}

Methods and Applications

\author{
Edited by
}

\section{David J. Carroll}

Florida Institute of Technology,

Melbourne, FL, USA 
Editor

David J. Carroll

Florida Institute of Technology

Melbourne, FL

USA

dcarroll@fit.edu

Series Editor

John M. Walker

University of Hertfordshire

Hatfield, Hert.

UK

ISSN: 1064-3745

e-ISSN: 1940-6029

ISBN: 978-1-58829-884-3

e-ISBN: 978-1-59745-202-1

DOI 10.1007/978-1-59745-202-1

Library of Congress Control Number: 2008938642

(C) Humana Press, a part of Springer Science+Business Media, LLC 2009

All rights reserved. This work may not be translated or copied in whole or in part without the written permission of the publisher (Humana Press, c/o Springer Science+Business Media, LLC, 233 Spring Street, New York, NY 10013, USA), except for brief excerpts in connection with reviews or scholarly analysis. Use in connection with any form of information storage and retrieval, electronic adaptation, computer software, or by similar or dissimilar methodology now known or hereafter developed is forbidden.

The use in this publication of trade names, trademarks, service marks, and similar terms, even if they are not identified as such, is not to be taken as an expression of opinion as to whether or not they are subject to proprietary rights.

Cover illustration: The image shows how a holding pipet is used to immobilize a zebrafish oocyte for microinjection. A typical holding pipet produced by flame polishing of a glass capillary is used to pick up and immobilize an unfertilized oocyte. Magnification is indicated by the bar which represents $100 \mu \mathrm{m}$. Photo credit: William H. Kinsey.

Printed on acid-free paper

springer.com 


\title{
Preface
}

\section{David J. Carroll}

\begin{abstract}
Cellular microinjection techniques have developed over the last century along with the evolution of other biological fields. For example, developmental biologists have used a variety of microinjection techniques to transfer cytoplasm between cells, inject antibodies and peptides, and express foreign genes in specific tissues to advance their understanding of cell specification and determination. Molecular biologists finely craft glass microneedles and tools for the manipulation of cells in order to study gene expression and communication between cells. As these techniques have matured, microinjection has become accessible and, thus, exploited by a larger segment of the scientific and medical community. As more and more information is gathered from the various genome projects, demand grows for methods to validate these new data. Microinjection can help address this need. In particular, microinjection has proven valuable for the confirmation and extension of in vitro results in an in vivo setting - the living cell. The technique has also found a home in the clinical setting, most obviously within the community of fertility specialists for in vitro fertilization methods and for those excited about the possibility of therapeutic cloning.

This book explores the use of microinjection for a wide range of scientific uses. There are special considerations for each application of microinjection - whether it is the injection of antibodies, fusion proteins, DNA, and in vitro-synthesized RNA or the production of transgenic animals. It is hoped that these methods will be of interest for all biologists for use in the research laboratory, as well as for clinicians interested in applying this powerful method for treatment in the clinic.
\end{abstract}

\section{A Brief History of Microinjection}

The technique of microinjection was born of necessity and owes its history to a combination of fields. Credit for the initial description of a coherent microinjection technique could be given to Marshall Barber, who developed methods for producing fine glass capillary pipettes for isolating and manipulating single bacterial cells $(1,2)$, or to the embryologist Laurent Chabry, credited with developing the glass microcapillary and micromanipulator as tools for his studies on teratology in ascidian blastomeres $(3,4)$. Barber incorporated techniques into his injection method that are still used today, including the first use of mercury for controlling the movement of small volumes of fluid (see below) and the use of a second pipette to hold the cells as the injection is completed $(5,6)$.

The technique of microinjection moved from being a useful method practiced by a few resourceful scientists to an exciting mainstream application when Gurdon and colleagues demonstrated that 
purified mRNA from one cell could be injected into the cytoplasm of another cell and actually get translated into protein (7). This was remarkable for several reasons: (1) the mRNA was stable, at least stable enough that it was capable of directing the synthesis of detectable levels of protein; (2) no special factors, other than the exogenous mRNA itself, were required for this to work; and (3) success was independent of the cell type of the donor RNA. In fact, species differences do not appear to matter, as they were able to obtain the synthesis of rabbit hemoglobin in Xenopus laevis oocytes.

Since then, the method of expressing protein from microinjected mRNA has been used to great advantage in studies for developmental biology, neurobiology, cell biology, and signal transduction, just to name a few. An excellent overview of this method is given by Douglas Melton (8), in which he explains why the oocyte (and the Xenopus oocyte, in particular) provides the perfect system for this to work, along with describing details of the current methods at that time. One great advantage of this system, compared to translation in vitro or by induced expression in bacteria, is that the mRNA is placed in a living eukaryotic cell so the protein is processed properly and subject to post-translational modification.

Of course, the technique is not only useful for microinjecting RNA into Xenopus oocytes. It has been utilized for transferring cytoplasm from one cell to another, such as was done in the experiments that led to the discovery that maturation promoting factor (MPF) was neither species nor cell-type specific (9-11). This fundamental work provided the groundwork for the eventual discovery of cyclins and cyclin-dependent kinases (12,13). Proteins have been injected into cells for the study of cell structure and function. One of the first examples of this utility was the microinjection of fluorescently labeled $\alpha$-actinin into living fibroblasts, allowing the visualization of this molecule integrating dynamically into the cytoskeleton (14). Of course, the concept of following labeled proteins in a living cell has since exploded with the availability of green fluorescent protein (GFP) vectors and protocols $(15,16)$.

One tremendous advantage of microinjection, when compared to other methods of introducing material into cells, such as electroporation or chemical membrane permeabilization, is the ability to be quantitative. Methods for quantitative microinjection have developed over the years, but began in earnest with a study by Hiramoto on the process of fertilization (17). In that study, live spermatozoa were microinjected into sea urchin eggs to develop an assay for the identification of a "substance or substances which trigger the train of fertilization reactions in the egg". No such substance was identified in that study ( see Chapter 2), but methods to precisely control and quantify the volume of the injection using a mercury-filled needle connected to a screw-controlled 
syringe were described. Hiramoto's basic method has been further refined (18-20), but is still being used today.

This book provides methods of microinjection coupled with modern molecular techniques, such as RNAi, morpholino antisense oligonucleotides, GFP expression, or the production of transgenic cells or animals, for example. However, the book also revisits classic uses of microinjection, such as mRNA expression or nuclear transfer, with modern twists.

\section{Book Content}

The classic technique of microinjecting Xenopus zygotes with mRNA prepared in vitro is revisited in Chapter 1 with a focus on studying proteins involved in the cell cycle. A discussion of the use of microinjection compared to other methods of manipulating proteins in a living cell is given. The chapter also provides consideration of choosing the appropriate plasmid vector with an eye toward downstream analysis of the effectiveness of the protein expression. This discussion should be very useful for investigators considering the use of mRNA microinjection for the first time.

In Chapter 2, a very clever method using a luciferase chimera to visualize the expression of a protein, $\mathrm{PLC} \zeta$, that causes calcium release and egg activation during fertilization in mammals is described (21). Methods are given for producing the luciferaselabeled cRNA, along with techniques for assessing the expression of the fusion protein by microscopy, which allows simultaneous imaging of fluorescent indicators (e.g., a $\mathrm{Ca}^{2+}$ indicator), or by luminometer for quantification of luciferase expression. This method could easily be applied to other molecules in any cell type that will express exogenous RNA. In particular, it promises to be useful for combining detection of low levels of protein expression with quantification of those molecules from a reasonable number of cells.

In Chapter 3, a very straightforward technique for using antisense morpholino oligos to specifically remove 14-3-3 proteins in Xenopus laevis is described. Morpholino oligos are nonionic DNA analogs that possess an altered phosphodiester backbone. This apparently makes them more resistant to nucleases and, because they are not charged, less likely to interact nonspecifically with proteins (22). This technique complements their earlier work in which the 14-3-3 proteins were studied using peptide inhibitors or dominant-interfering GST fusion proteins (23). Their method utilizes morpholinos that target the initiation codon and the 22 ribonucleotides immediately downstream, 
which may produce more effective inhibition. This chapter outlines methods for (1) procuring the Xenopus sperm and eggs, (2) setting up and using a pressure microinjection apparatus with the Xenopus one- or two-cell embryo, (3) for analyzing and quantifying protein levels by western blotting, and (4) for analyzing the phenotypic effects of the morpholino injections. An alternate strategy for morpholino design that targets the $5^{\prime}$ untranslated region of the target gene is also discussed.

Methods for microinjecting peptides and fusion proteins into Xenopus laevis oocytes are given in Chapter 4 . Following a very clear description of ovary dissection and oocyte procurement by collagenase treatment, the procedure for performing rapid microinjections into the Xenopus oocyte is given. Accompanied by excellent photographs, this chapter explains the process in detail from start to finish. For example, in the text and in the Notes section, suggestions are given regarding the exact size for the tip of the microinjection needle and when the needle should be changed, the maximum volume and concentration of protein that should be injected into an individual oocyte, and how to deal with multiple injections into the same oocyte. This type of detail fills the chapter and will help other investigators maximize success when they adopt this method.

A method to combine microinjection with western blot analysis is described in Chapter 5. In this procedure, single oocytes are microinjected with a pharmacological inhibitor of RAS and then assayed for the presence of phosphorylated mitogen-activated protein kinase (pMAPK), which indicates an active enzyme, by immunoblotting. Thus far, this has been applied only for the analysis of the pMAPK during oocyte maturation and fertilization in starfish oocytes. However, it should also be useful in other large cells (such as Xenopus oocytes) and, as detection methods improve, it could easily be adapted to the analysis of other proteins in other systems. Analysis of single cells should prove useful because it eliminates the variability inherent to the analysis of cell populations.

This book considers the use of many different model systems, including the zebrafish Danio revio. The zebrafish has proven extremely useful for experimental study because it is amenable to genetic studies, the embryo develops rapidly, and it is optically clear (you can see inside). The zebrafish zygote and early embryo have been utilized as a system for microinjection because of the large size of the eggs and the ease with which the adults are maintained. However, for a variety of reasons it would be advantageous to inject the mature egg prior to fertilization and this has proven difficult. In Chapter 6, a practical method for microinjection, and subsequent insemination, of the unfertilized zebrafish egg is reported. This will open up more opportunities for exploiting an already useful model system. 
In the first method (Chapter 7) to deal with a 'non-gamete' system, techniques for antibody microinjection and oligofectamine transfection of RNAi for analysis of protein function in living tissue culture cells are compared. The chapter is very detailed which should allow these methods to be adapted to many different situations. The chapter also features a very extensive and useful notes section, detailing specifics of each of the methods.

Methods for developing recombinant cells lines by microinjection into the nucleus are presented in Chapter 8. This very interesting article demonstrates that introduction of plasmid DNA for the GFP, in several cell types, leads to stable transduction as assayed by flow cytometry of GFP fluorescence up to 1 month after microinjection! The chapter details methods that could be adapted to virtually any cell type and for any DNA. Conditions for optimizing the production of the transformed cells lines are tested in this chapter and detailed notes are given to help any investigator interested in attempting this method.

Different experimental methods, including transposons, I-SceI meganuclease, and direct injection of linearized DNA, have been used to produce transgenic Xenopus for the study of a variety of problems (24-26). However, these methods rely upon random insertion into the Xenopus genome or produce multiple copies. In Chapter 9, a technique is described for the targeted insertion of a single copy of the gene of interest into Xenopus laevis using phiC3 1 integrase. By incorporating insulator sequences into the plasmid design, they improve expression from the reporter gene making this method extremely useful for anyone wishing to express a transgene at approximately endogenous levels.

Transgenics are also the topic of Chapter 10. A method for producing transgenic Caenorhabditis elegans by microinjecting DNA directly into the hermaphrodite gonad is provided. For those not familiar with C. elegans, this chapter provides an excellent introduction to this powerful system. It recounts the basic reproductive biology of the worm and includes a discussion of applications for microinjection. Techniques for cultivating the worms and special hints for maximizing success of microinjection are explained in detail.

One of the great advantages of using microinjection to introduce molecules into living cells is the ability to perform quantitative experiments. Chapter 11 gives detailed methods for the quantitative microinjection of picoliter quantities into mouse oocytes and eggs in dishes on an inverted microscope. The technique is described in wonderful detail and covers all aspects from making the glass bottom dishes that hold the oocytes to the injection process itself. There are several items of note in the chapter. I particularly enjoyed learning how to use an old record player to construct a beveler capable of producing a nice $1-2 \mu \mathrm{m}$ tip. But then, what will I do with my old Pink Floyd records? 
For precision, the microinjection needles need to include a mechanism for controlling the rate of injection. Two methods are given in Chapter 11 to achieve this: (1) using mercury to backfill the micropipette and relying upon the mercury to transduce and control pressure and (2) constructing a microneedle with a constriction near the tip which reduces fluid movement and provides fine control of the injection. Both types of microinjection needles can be used in the same overall system.

A similar microinjection system is described in Chapter 12, with modifications that allow for injection of the mouse oocyte within the complete follicle. Because the mouse oocyte exists within the follicle when in the ovary, it is intimately associated with the surrounding follicle cells until after ovulation. This relatively new method allows for the microinjection to occur while the oocyte is cultured within the intact follicle under more physiologically relevant conditions. By microinjecting the follicle-enclosed oocytes, this group has been able to discover the mechanism(s) that maintain the immature oocyte arrested in meiosis and also to begin exploring the signaling mechanisms that are responsible for the reinitiation of meiosis (27-29). The technique is quite revolutionary and the concept of maintaining the proper physiological environment, as much as possible, is one that is applicable to all situations. In this chapter, you will also learn what type of music is most enjoyed by mouse oocytes.

In some cases, microinjection would be very useful but not considered because of the perceived difficulty of injecting sufficient numbers of cells for further analysis. Chapter 13 describes a pressure-based method of injecting zygotes of the sea urchin Paracentrotus lividus. Using this method, up to several hundred embryos can be injected in a single session. In addition to the microinjection method, this chapter also describes experimental methods for perturbing gene function by either (1) producing and microinjecting synthetic mRNA produced in vitro, or (2) preparing linear DNA amplified by PCR for direct microinjection into the embryo. The advantages and disadvantages of these two different methods are discussed.

The final two chapters describe practical uses of the technique of microinjection. Methods for imaging human gametes and zygotes after intracytoplasmic sperm injection (ICSI) are presented in Chapter 14. The techniques focus on the identification of cytoskeletal elements and the role these components play during fertilization. Procedures are given in great detail for the removal of follicle cells and the zona pellucida, and fixation procedures optimized for fluorescence immunocytochemistry and for examination by conventional electron microscopy and ultrastructural immunolocalization.

Chapter 15 presents a method for somatic cell nuclear transfer (SCNT) in the mouse. This article directly addresses the fact 
that cloning by SCNT has always been difficult and inefficient (30, 31 ). In the protocol described here, donor nuclei from cumulus cells are injected directly into mouse oocyte. While this has been accomplished before, the Kishigami and Wakayama protocol results in a twofold to fivefold improvement in embryo developmental rates by the inclusion of trichostatin A, a histone deacetylase inhibitor. The TSA may 'reprogram' the somatic cell nuclei, making them more amenable to the early developmental program. Also significant in Chapter $\mathbf{1 5}$ is a description of the use of a piezo-actuated micromanipulator that allows the use of larger microinjection needle tips with less damage to the oocyte.

\section{Conclusion}

The methods described in this book should allow any lab to incorporate the technique of microinjection into their experimental repertoire. Whether DNA, RNA, or protein is the molecule of interest, microinjection provides a mean of studying function within the context of the living cell. The technology is remarkably accessible and relatively inexpensive, while the possibilities are virtually endless.

\section{Acknowledgments}

I thank Dr. Laurinda Jaffe of the University of Connecticut Health Center for introducing me to microinjection and other fun things; and to Dr. John Walker of the University of Hertfordshire for his patience and guidance during the development of this book.

\section{References}

1. Barber, M. (1904) A new method of isolating microorganisms. J. Kans. Med. Soc. 4, 489-494.

2. Barber, M.A. (1911) A technique for the inoculation of bacteria and other substances into living cells. J. Infect. Dis. 8, 348-360.

3. Chabry, L. (1887) Contribution a l'embryologie normal et teratologique des Ascidiens simples. Jour. de l'Anat. et de Physiol. 25, 167.
4. Fischer, J-L. (1990) Experimental embryology in France. Int. J. Dev. Biol. 34, 11-23.

5. Barber, M.A. (1914) The pipette method in the isolation of single microorganisms and in the inoculation of substances into living cells. Philippine J. Sci. B. 9, 307-360.

6. Korzh, V. and Strhle, U. (2002) Marshall Barber and the century of microinjection: from cloning of bacteria to cloning of everything. Differentiation 70, 221-226. 
7. Lane, C.D., Marbaix, G., and Gurdon, J.B. (1971) Rabbit haemoglobin synthesis in frog cells: the translation of reticulocyte 9S RNA in frog oocytes. J. Mol. Biol. 61, 73-91.

8. Melton, D.A. (1987) Translation of messenger RNA in injected frog oocytes. Meth. Enzymol. 152, 288-296.

9. Masui, Y., and Markert, C.L. (1971) Cytoplasmic control of nuclear behavior during meiotic maturation of frog oocytes. J. Exp. Zool. 177, 129-145.

10. Reynhout J.K. and Smith L.D. (1974) Studies on the appearance and nature of a maturation-inducing factor in the cytoplasm of amphibian oocytes exposed to progesterone. Dev. Biol. 38, 394-400.

11. Gurdon, J.B. (1968) Changes in somatic cell nuclei inserted into growing and maturing amphibian oocytes. J. Embryol. Exp. Morphol. 20, 401-414.

12. Evans, T., Rosenthal, E.T., Youngblom, J., Distel, D., Hunt, T. (1983) Cyclin: a protein specified by maternal mRNA in sea urchin eggs that is destroyed at each cleavage division. Cell 33, 389-396.

13. Nurse, P., Thuriaux, P., and Nasmyth, K. (1976) Genetic control of the cell division cycle in the fission yeast Schizosaccharomyces pombe. Mol. Gen. Genet. 146, 167-178.

14. Feramisco, J.R. (1979) Microinjection of fluorescently labeled a-actinin into living fibroblasts. Proc. Natl. Acad. Sci. USA. 76, 3967-3971.

15. Prasher, D.C., Eckenrode, V.K., Ward, W.W., Prendergast, F.G., Cormier, M.J. (1992) Primary structure of the Aequorea victoria greenfluorescent protein. Gene. 111, 229-233.

16. Shimomura, O. (2005) The discovery of aequorin and green fluorescent protein. $J$. Microsc. 217, 1-15.

17. Hiramoto, Y. (1962) Microinjection of the live spermatozoa into sea urchin eggs. Exp. Cell Res. 27, 416-426.

18. Kiehart, D.P. (1982) Microinjection of echinoderm eggs: apparatus and procedures. Methods Cell Biol. 25, 13-31.

19. Kishimoto, T. (1986) Microinjection and cytoplasmic transfer in starfish oocytes. Methods Cell Biol. 27, 379-394.

20. Jaffe, L.A., and Terasaki, M. (2004) Quantitative microinjection of oocytes, eggs, and embryos. Methods Cell Biol. 74, 219-242.
21. Saunders, C.M., Larman, M.G., Parrington, J., Cox, L.J., Royse, J., Blayney, L.M., Swann, K., and Lai F.A. (2002) PLC $\zeta$ : a sperm-specific trigger of $\mathrm{Ca}^{2+}$ oscillations in eggs and embryo development. Development 129, 3533-3544.

22. Corey, D.R., and Adams, J.M. (2001) Morpholino antisense oligonucleotides: tools for investigating vertebrate development. Genome Biol. 2(5), reviews1015.1-1015.3.

23. Wu, C. and Muslin, A.J. (2002) Role of 143-3 proteins in early Xenopus development. Mech. Dev. 119, 45-54.

24. Yergeau, D.A., and Mead, P.E. (2007) Manipulating the Xenopus genome with transposable elements. Genome Biol. 8 (Suppl 1), S11.

25. Pan, F.C., Chen, Y., Loeber, J., Henningfeld, K., Pieler, T. (2006) I-SceI meganuclease-mediated transgenesis in Xenopus. Dev Dyn. 235, 247-252.

26. Etkin, L., Pearman, B., Roberts, M., Bektesh, S.L. (1984) Replication, integration and expression of exogenous DNA injected into fertilized eggs of Xenopus laevis. Differentiation 26, 194-202.

27. Mehlmann, L.M., Jones, T.L., Jaffe, L.A. (2002) Meiotic arrest in the mouse follicle maintained by a Gs protein in the oocyte. Science 297, 1343-1345.

28. Mehlmann, L.M., Saeki, Y., Tanaka, S., Brennan, T.J., Evsikov, A.V., Pendola, F.L., Knowles, B.B., Eppig, J.J., Jaffe, L.A. (2004) The Gs-linked receptor GPR3 maintains meiotic arrest in mammalian oocytes. Science 306, 1947-1950.

29. Freudzon, L., Norris, R.P., Hand, A.R., Tanaka, S., Saeki, Y., Jones, T.L., Rasenick, M.M., Berlot, C.H., Mehlmann, L.M., Jaffe, L.A. (2005) Regulation of meiotic prophase arrest in mouse oocytes by GPR3, a constitutive activator of the Gs $\mathrm{G}$ protein. J. Cell Biol. 171, 255-265.

30. Tian, X.C., Kubota, C., Enright, B., Yang, X. (2003) Cloning animals by somatic cell nuclear transfer - biological factors. Reprod Biol Endocrinol. 1, 98.

31. Campbell, K.H., Fisher, P., Chen, W.C., Choi, I., Kelly, R.D., Lee, J.H., Xhu, J. (2007) Somatic cell nuclear transfer: Past, present and future perspectives. Theriogenology. 68 Suppl 1, S214-S231. 


\section{Contents}

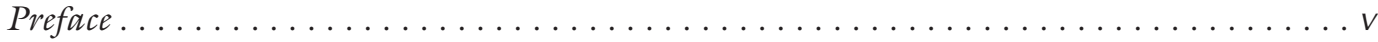

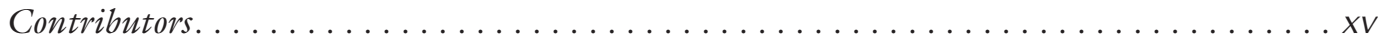

1 Expression of Exogenous mRNA in Xenopus laevis Embryos for the Study of

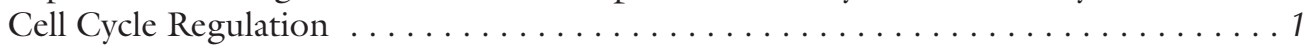
Jill C. Sible and Brian N. Wroble

2 Use of Luciferase Chimaera to Monitor PLC $\zeta$ Expression in Mouse Eggs . . . . . . 17 Karl Swann, Karen Campbell, Yuansong Yu, Christopher Saunders and F. Anthony Lai

3 Analysis of 14-3-3 Family Member Function in Xenopus Embryos by Microinjection of Antisense Morpholino Oligos . . . . . . . . . . . . 31 Jeffrey M. C. Lau and Anthony J. Muslin

4 A Microinjectable Biological System, the Xenopus Oocyte, as an Approach to Understanding Signal Transduction Protein Function $\ldots \ldots \ldots \ldots \ldots \ldots \ldots$ Katia Cailliau and Edith Browaeys-Poly

5 Combining Microinjection and Immunoblotting to Analyze MAP Kinase Phosphorylation in Single Starfish Oocytes and Eggs . . . . . . . . . . . . 57 David J. Carroll and Wei Hua

6 Analysis of Signaling Pathways in Zebrafish Development by Microinjection . . . . . . 67 William H. Kinsey

7 Protein Inhibition by Microinjection and RNA-Mediated Interference in Tissue Culture Cells: Complementary Approaches to Study Protein Function . . . . . . . . . . 77 Jane R. Stout, Rania S. Rizk, and Claive E. Walczak

8 DNA Delivery by Microinjection for the Generation of Recombinant Mammalian Cell Lines . . . . . . . . . . . . . . . . . . . . . . . . . . . . . . . 99 Sebastien Chenuet, Madiha Derouazi, David Hacker and Florian Wurm

9 Bacteriophage $\phi$ C31 Integrase Mediated Transgenesis in Xenopus laevis for Protein Expression at Endogenous Levels . . . . . . . . . . . . . . . . . . . 113 Bryan G. Allen and Daniel L. Weeks

10 Germline Transformation of Caenorbabditis elegans by Injection . . . . . . . . 123 Pavan Kadandale, Indrani Chatterjee and Andrew Singson

11 Quantitative Microinjection of Mouse Oocytes and Eggs . . . . . . . . . . 135 Douglas Kline

12 Microinjection of Follicle-Enclosed Mouse Oocytes . . . . . . . . . . . . . . 157 Laurinda A. Jaffe, Rachael P. Norris, Marina Freudzon, William J. Ratzan, and Lisa M. Meblmann

13 Functional Studies of Regulatory Genes in the Sea Urchin Embryo . . . . . . . . . . 175 Vincenzo Cavalieri, Maria Di Bernardo, and Giovanni Spinelli 
xiv Contents

14 Exploring the Cytoskeleton During Intracytoplasmic Sperm Injection in Humans . . . . . . . . . . . . . . . . . . . . . . . . . 189 Vanesa $\Upsilon$. Rawe and Héctor Chemes

15 Somatic Cell Nuclear Transfer in the Mouse . . . . . . . . . . . . . . . . . . . . 207 Satoshi Kishigami and Terubiko Wakayama

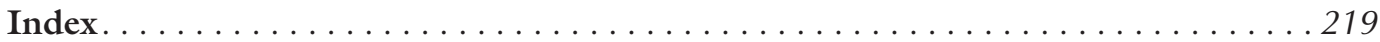




\section{Contributors}

Bryan G. Allen - Department of Biochemistry, University of Iowa, Iowa City, IA, USA

Edith Browaeys-Poly • Université des Sciences et Technologies de Lille, Laboratoive de Régulation des Signaux de Division, Villeneuve d'Ascq Cedex, France

Katia CAIlliau - Université des Sciences et Technologies de Lille, Laboratoire de Régulation des Signaux de Division, Villeneuve d'Ascq Cedex, France

Karen Campbell - Department of Obstetrics and Gynaecology, School of Medicine, Cardiff University, Cardiff, UK

David J. Carroll - Department of Biological Sciences, Florida Institute of Technology, Melbourne, FL, USA

Vincenzo Cavalieri • Dipartimento di Biologia Cellulare e dello Sviluppo “A. Monroy”, Università di Palermo, Palermo, Italy

IndRANi ChatTerJeE • Waksman Institute, Rutgers University, Piscataway, NJ, USA

Héctor Chemes - CEDIE, Laboratorio de Fisiologí y Patología Testicular, Hospital de Niños 'Ricardo Gutiérrez', Buenos Aires, Argentina

Sebastien Chenuet • École Polytechnique Féderale de Lausanne, EPFL-SV-IBI-LBTC, Lausanne, Switzerland

Madiha Derouazi • École Polytechnique Féderale de Lausanne, EPFL-SV-IBI-LBTC, Lausanne, Switzerland

Maria Di Bernardo • Istituto di Biomedicina e Immunologia Molecolare "A. Monroy", Consiglio Nazionale delle Ricerche, Palermo, Italy

Marina Freudzon • Department of Cell Biology, University of Connecticut Health Center, Farmington, CT, USA

DAvid HaCKer • École Polytechnique Féderale de Lausanne, EPFL-SV-IBI-LBTC, Lausanne, Switzerland

Wei Hua - College of Aqua-life Science and Technology, Shanghai Fisheries University, Shanghai, China

Laurinda A. JAFFe - Department of Cell Biology, University of Connecticut Health Center, Farmington, CT, USA

Pavan KadAndale - Waksman Institute, Rutgers University, Piscataway, NJ, USA

William H. Kinsey • Department of Anatomy and Cell Biology, University of Kansas Medical Center, Kansas City, KS, USA

Satoshi Kishigami • RIKEN, Center for Developmental Biology, Kobe, Japan

Douglas Kline • Department of Biological Sciences, Kent State University, Kent, OH, USA

F. Anthony Lai - Cell Signaling Laboratory, Wales Heart Research Institute, School of Medicine, Cardiff University, Cardiff, UK

Jefrerey M.C. LAU • Center for Cardiovascular Research, Department of Medicine, Department of Cell Biology \& Physiology, Washington University School of Medicine, St. Louis, MO, USA 
Lisa M. Mehlmann - Department of Cell Biology, University of Connecticut Health Center, Farmington, CT, USA

Anthony J. Muslin • Center for Cardiovascular Research, Department of Medicine, Department of Cell Biology \& Physiology, Washington University School of Medicine, St. Lonis, MO, USA

RaChael P. NorRis • Department of Cell Biology, University of Connecticut Health Center, Farmington, CT, USA

William J. RATZAN • Department of Cell Biology, University of Connecticut Health Center, Farmington, CT, USA

VANESA Y. RAwe - Centro de Estudios en Ginecología y Reproducción (CEGyR), Buenos Aires, Argentina

RANIA S. RIZK • Department of Biology, Indiana University, Bloomington, IN, USA

Christopher SAunders • Cell Signaling Laboratory, Wales Heart Research Institute, School of Medicine, Cardiff University, Cardiff, UK

Jill C. Sible - Department of Biological Sciences, Virginia Polytechnic Institute and State University, Blacksburg, VA, USA

Andrew Singson • Waksman Institute, Rutgers University, Piscataway, NJ, USA

Giovanni Spinelli • Dipartimento di Biologia Cellulare e dello Sviluppo "A. Monroy", Università di Palermo, Palermo, Italy

JANE R. STOUT - Department of Biochemistry and Molecular Biology, Indiana University Medical Sciences, Bloomington, IN, USA

Karl Swann • Department of Obstetrics and Gynaecology, School of Medicine, Cardiff University, Cardiff, UK

Teruhiko Wakayama - RIKEN, Center for Developmental Biology, Kobe, Japan

Claire E. WalczaK - Department of Biochemistry and Molecular Biology, Indiana University Medical Sciences, Bloomington, IN, USA

DANIEL L. WeEKs • Department of Biochemistry, University of Iowa, Iowa City, IA, USA

Brian N. Wroble - Department of Biological Sciences, Virginia Polytechnic Institute and State University, Blacksburg, VA, USA

Florian Wurm • École Polytechnique Féderale de Lausanne, EPFL-SV-IBI-LBTC, Lausanne, Switzerland

Yuansong Yu - Department of Obstetrics and Gynaecology, School of Medicine, Cardiff University, Cardiff, $U K$ 